\title{
Pathogenic Interplay Between Chlamydia trachomatis and Neisseria gonorrhoeae that Influences Management and Control Efforts-More Questions than Answers?
}

\author{
Cory Ann Leonard ${ }^{1} \cdot$ Robert V. Schoborg $^{2} \cdot$ Nicola Low $^{3} \cdot$ Magnus Unemo $^{4} \cdot$ Nicole Borel $^{1}$
}

Published online: 12 July 2019

(C) The Author(s) 2019

\begin{abstract}
Purpose of Review To emphasize key gaps in knowledge impacting efforts to control single infection and co-infections with Chlamydia trachomatis (CT) and Neisseria gonorrhoeae (NG), the most common bacterial sexually transmitted infections (STIs) worldwide.

Recent Findings Clinical and epidemiological studies describe gaps in understanding about female rectal CT infection, screening effectiveness, pelvic inflammatory disease, and influence of the microbiome. For NG, gaps in knowledge include factors increasing incidence in men who have sex with men, correlations between treatment and antibiotic resistance, the role of pharyngeal infection, and microbiome influence. CT/NG co-infections are poorly understood, and adequate models to explore pathophysiological consequences of co-infection urgently needed. The sole existing CT/NG co-infection mouse model showed that $\mathrm{CT} / \mathrm{NG}$ interactions in vivo modulate host response and NG load/shedding — encouraging further consideration of this model and potential alternatives.

Summary We stress key challenges in controlling these important STIs. Appropriate, quality-assured animal models are essential to improve understanding of the pathogenic interplay in CT/NG co-infections.
\end{abstract}

Keywords Chlamydia trachomatis $\cdot$ Neisseria gonorrhoeae $\cdot$ Co-infection $\cdot$ Mouse model

This article is part of the Topical Collection on Influences of Hormones and Other Microorganisms on Genital Tract Pathogens

Cory Ann Leonard

cory.leonard@uzh.ch

1 Institute of Veterinary Pathology, Department of Pathobiology, Vetsuisse Faculty, University of Zurich, Winterthurerstrasse 268, CH-8057 Zurich, Switzerland

2 Department of Biomedical Sciences, Center of Excellence for Inflammation, Infectious Disease and Immunity, Quillen College of Medicine, East Tennessee State University, Box 70579, Johnson City, TN 37614-0579, USA

3 Institute of Social and Preventive Medicine (ISPM), University of Bern, Mittelstrasse 43, 3012 Bern, Switzerland

4 World Health Organization Collaborating Centre for Gonorrhoea and Other Sexually Transmitted Infections, Department of Laboratory Medicine, Faculty of Medicine and Health, Örebro University, SE-70185 Örebro, Sweden

\section{Introduction}

Chlamydia trachomatis (CT) and Neisseria gonorrhoeae (NG) cause the most commonly reported bacterial sexually transmitted infections (STIs) in humans worldwide, with an estimated 127 million new cases of chlamydia and 87 million of gonorrhea among adults in 2016, according to the World Health Organization (WHO) [1]. The primary site of infection for both bacteria is the columnar epithelium of the endocervix in women and the urethra in men; both also infect the rectum, pharynx, and conjunctiva and can be transmitted from an infected mother during pregnancy or delivery [2]. CT/NG coinfections are more frequent than would be expected by chance, and mathematical modeling studies suggest that biological interactions between the two increase susceptibility and/or transmissibility [3•]. In this review, we highlight some gaps in knowledge that challenge the effective management and control of these STIs. We focus on clinical or epidemiological studies and data from animal models published from 2014 to 2019, for both single infections and co-infections. 


\section{The Two Most Commonly Reported Bacterial STIs: Chlamydia and Gonorrhea}

\section{Chlamydia}

The prevalence of CT, measured in surveys in the general population in high-income countries, is $\sim 3-4 \%$ in young adults $[4,5]$. Reported numbers of CT infections are increasing and/or high in many countries. In the United States of America (USA), more than 1.7 million cases of CT were reported to the Centers for Disease Control and Prevention (CDC) in 2017, nearly $7 \%$ more than in 2016 [6]. The highest rate of diagnoses is among women aged 15-24 years, reflecting recommendations for yearly testing in this group [6]. The majority of women and up to half of men infected with CT are asymptomatic, so infections often remain undiagnosed and unreported [2]. In women, cervical CT infection can ascend from the endocervix into the endometrium and fallopian tubes, resulting in pelvic inflammatory disease (PID), which can then cause tubal factor infertility (TFI) and ectopic pregnancy (EP). CT is associated with clinical PID in around $20 \%$ of cases; other STI agents, including NG, are also implicated [7]. In men, urethritis is the most frequent STI syndrome, with CT causing $15-40 \%$ of cases. Among MSM attending clinics in high-income countries, about $10 \%$ have CT detected in the rectum [8-11].

Doxycycline (a tetracycline) and azithromycin (a macrolide) are treatments of choice for CT infections [12-14]. Stable homotypic antibiotic resistance in CT in clinical specimens has not been reported to date [15], in stark contrast to multidrug-resistant NG strains circulating and increasing worldwide [16]. However, repeated detection of CT after treatment can be common, resulting from failure to cure the infection, poor treatment compliance, test of cure performed too early and/or detection of DNA/RNA from nonviable organisms, or re-infection from an untreated or new infected partner $[17,18]$.

\section{Chlamydia-Critical Gaps in Knowledge}

Management and control of CT infection remain continuously challenging [4, 19]. Reasons are likely manifold, but there is prominent discussion about the potential importance of rectal CT infection in women in particular [20, 21]. Asymptomatic rectal CT has been hypothesized to be a reservoir of untreated infection, hindering chlamydia control [22]. Information is limited, however, about the clinical relevance of CT in anal canal swabs in females, when detected by a nucleic acid amplification test (NAAT) that do not distinguish between viable bacteria and CT DNA/RNA from non-viable bacteria. NAATs are often used as the sole diagnostic tool because of their high sensitivity [23], but CT-positive results could come from nonviable nucleic acid transferred from genital secretions on fingers or toilet paper. A systematic review of studies of anal canal specimens analyzed by NAAT reported an average of $6 \%$ (95\% CI 3-9\%) CT-positive [23]. The finding that detection of CT in anal canal swabs is as common in women who report anal intercourse as those who do not [20,23] is more consistent with detection of nucleic acid than with infection. In mouse models of CT infection and treatment, rectal CT is more refractory to antibiotic treatment particularly azithromycin than genital CT [24]. In a systematic review of observational studies in humans, doxycycline eradicated CT from anal canal specimens more often than azithromycin, but very few women were included in the studies [25]. Autoinfection from the female rectum to the cervix has also been suggested as a reason for presumed treatment failure, with infection arising through oral ingestion and persisting in the lower gastrointestinal tract [24]. A 2018 study of human gastrointestinal biopsy tissue found CT in the appendix of one female specimen, but this was compatible with sexually transmitted ascending infection [26], and there is no empirical evidence of autoinfection. A prospective cohort study in the Netherlands (FemCure), which will collect specimens for routine NAATs, PCR for detection of CT viability, culture, and genotyping, should help shed light on the potential role of rectal CT in women [27].

There are still gaps in evidence about the effectiveness of widespread screening for chlamydia to prevent reproductive tract complications and reduce infection prevalence [4]. Public health agencies in many high-income countries recommend screening all sexually active women or women and men under age 25-29 [6, 28, 29]. Definitive evidence about the effects of screening on CT transmission is absent because there were no randomized controlled trials (RCTs) before screening was first recommended in the 1980s and 1990s in Sweden and the USA, respectively [30]. Repeated estimates of CT prevalence in the general population have remained stable during the twenty-first century in adults in Great Britain [31] and the USA [32]. Two trials of strategies to increase general screening uptake in women and men aged 15-29 years did not find reductions in estimated $\mathrm{CT}$ prevalence [33, 34]. A study of CT screening uptake in young adults in Britain indicated that at least $25 \%$ of women and approximately $50 \%$ of men with CT risk factors had not been tested for CT in the last year [35]. Targeting women at highest risk for complications has therefore been suggested as a more effective strategy [19]. There is stronger evidence for an effect of screening for CT in the prevention of PID [4], but identification of women at highest risk of progression to PID is challenging [36]. Notably, a correlation between blood transcriptional profiles of CT- and/or NG-infected and uninfected women and clinical outcome was recently demonstrated [37], showing progress toward identifying those at risk for damaging long-term sequelae. 
The interaction between STIs and the vaginal microbiome has gained attention as a potential factor for infection acquisition, transmission, and progression. Maintenance of a lactobacilli-dominant, inflammation-free environment could advance prevention of STIs and their adverse outcomes. A systematic review and meta-analysis, published in 2019, indicated that a vaginal microbiota dominated by Lactobacillus crispatus, L. iners, L. gasseri, and/or L. jensenii might have a role in protection against CT infection [38]. In line with these findings, a study that tested stored samples collected for vaginitis diagnosis found that those with bacterial vaginosis, either with or without concomitant Candida species infection, according to the BD MAX Vaginal Panel test, had an approximately $25 \%$ STI positivity rate, while those without bacterial vaginosis had an approximately $8 \%$ STI positivity rate [39]. This research is in its infancy and vaginal health is seldom routinely evaluated clinically. Thus, the impact of the vaginal microflora on CT (and NG) infection remains largely unclear [40]. However, microbiota-mediated defense against pathogenic intestinal bacterial infection has received considerably more attention (as reviewed in [41]) and might inform our future understanding of the potential protective role of the vaginal microbiome.

\section{Gonorrhea}

Though the prevalence of NG in the general population in high-income countries $(<0.5 \%)$ is much lower than that of CT [42], reports of NG diagnoses are increasing faster than those for CT. In the USA, in 2017, over 555,000 cases of NG were reported to $\mathrm{CDC}$, a rate increase of almost $19 \%$ from the previous year and approximately $75 \%$ since 2009 [6]. Rates of reported NG were higher in men than in women, a finding attributable, in part, to the higher proportion of symptomatic infection (urethritis) in men and the high prevalence of NG in MSM [6]. In the European Union/European Economic Area (EU/EEA), the number of NG cases has increased by more than $200 \%$ since 2008 , with the highest number of cases in the UK, France, the Netherlands, and Spain [43]. In this decade, substantial increases in NG cases occurred among MSM as well as among heterosexual men and women [43]. As with CT, untreated cervical NG infections may progress to the upper reproductive tract, contributing to PID, TFI, EP, and chronic pelvic pain [44].

In contrast to $\mathrm{CT}, \mathrm{NG}$ antimicrobial resistance is widespread, developing rapidly with each successive treatment regimen [19]. Dual ceftriaxone/azithromycin therapy, a treatment regimen that should also eradicate concurrent $\mathrm{CT}$ infection, is the recommended regimen for empirical treatment in many countries [19]. However, ceftriaxone susceptibility is decreasing in European countries not yet reporting overt ceftriaxone resistance [16, 45] and high-level azithromycinresistant strains have been spreading in some settings [46].
Alarmingly, with the emergence of confirmed ceftriaxoneresistant NG strains [47], untreatable NG might be anticipated in the near future [47-49].

\section{Gonorrhea-Critical Gaps in Knowledge}

Antiretroviral drugs, given as treatment for HIV infection and as pre-exposure prophylaxis (PrEP) to prevent acquisition of HIV, have been associated with increases in NG in MSM [50]. If drugs, rather than condoms, are the main method that MSM use to prevent HIV, HIV and STI prevention have been decoupled. The resultant reduced condom use and increases in other risky sexual practices will result in increased transmission of STIs, including NG, CT, syphilis, and Mycoplasma genitalium [19, 51, 52]. Sexual network analysis might be a useful tool in determining factors important in the spread and prevalence of STIs [53]. Frequent screening for STIs for MSM on PrEP is recommended, but a systematic review of observational studies, published in 2018, found no evidence of reductions in test positivity for either NG or CT [54], indicating that further study of STI screening efficacy to prevent STIs in MSM on PrEP is needed.

The emergence of highly antimicrobial-resistant NG is one of the most pressing public health concerns for STI control. Understanding the factors influencing selection, spread, and fitness of antimicrobial resistance in NG is critical to inform our continued efforts to curtail the emergence and global spread of multidrug-resistant, extensively drug-resistant, and potentially untreatable NG. Mathematical modeling indicates that the spread of antimicrobial-resistant NG in some settings may be explained by higher treatment rates, rather than differences in numbers of sexual partners, and is more common in MSM than in heterosexual men [55]. NG antimicrobial resistance, or decreased susceptibility, is also positively correlated with population-level antibiotic consumption rate [56], a finding that has been shown for other bacteria, such as Staphylococcus and enteric bacteria [57]. It has been postulated that "bystander selection" by exposure to antibiotics other than those specifically targeting NG infection may play a role in the emergence of antimicrobial-resistant $\mathrm{NG}$, in addition to the "direct selection" of NG-therapeutic antibiotics. This has important implications for public health policy dependent on the degree to which both kinds of selection contribute to NG antimicrobial resistance [58]. Additionally, the prevalence of antimicrobial-resistant NG increases with age and is lower in some black minority ethnic groups than the white population in high-income groups, indicating that risk factors for antimicrobial-resistant NG infection are distinct from those for NG infection in general [59].

There is increasing interest in extra-genital NG infection sites, particularly the pharynx, as an NG transmission source. Pharyngeal NG is largely asymptomatic, often undetected and frequently exposed to anti-NG antibiotics at levels suboptimal 
for clearance [60]. About 6\% of MSM have pharyngeal NG $[8,61]$, even in the absence of NG positivity at the rectal and urogenital sites, so lack of pharyngeal NG testing will result in missed infections in MSM [62]. A 2019 study from a single STD clinic in the USA found NAAT-detected NG in about $3 \%$ of heterosexual women and men reporting extra-genital sexual activity, suggesting a potentially important role in heterosexual NG transmission [63]. In a study of more than 2200 patients with pharyngeal NG in the Netherlands, almost $90 \%$ of patients remained infected in the time (median 10 days) between original sampling for NG diagnosis and subsequent return for therapy [64]. Studies among MSM in Australia confirm the role of pharyngeal NG as a likely source of urethral $\mathrm{NG}$ [65] and suggest a role for tongue kissing/saliva in NG transmission from pharynx to pharynx $[61,62,65]$. Considering the correlation between pharyngeal carriage with $\mathrm{NG}$ and antimicrobial resistance [59], additional study of pharyngeal NG may be important to understand the development of NG antibiotic resistance [66].

\section{Chlamydia and Gonorrhea Co-infection-Potentially Important Interactions}

$\mathrm{CT} / \mathrm{NG}$ co-infection is common, with around $10-40 \%$ of those with NG infection being concomitantly CT infected [67]. In most cases, the proportion of people with NG who have CT co-infection is higher than the proportion of people with CT who have NG [68], most likely reflecting higher CT prevalence. Mathematical modeling suggests that co-infection occurs too frequently to be random [3•], but the impact of coinfection on CT and NG epidemiology and pathogenesis is poorly understood. Pathogen-pathogen and pathogen-host interactions specific to co-infection may also affect interpretation of studies about transmission, re-infection, treatment failure, pathogenic immune response, and, importantly, vaccine development [69] — which may ultimately impact treatment and vaccine efficacy. There are substantial gaps in our knowledge of factors associated with prevalence of co-infection and the role co-infection may play in acquisition, pathogenesis, bacterial load and transmission, and disease course and severity for these two important bacterial STIs. Although many studies have examined different aspects of these issues, the reported findings are often contradictory.

Factors associated with $\mathrm{CT} / \mathrm{NG}$ co-infection vary across studies/populations and include sex, age, sex work, and drug/alcohol use [70-72]. MSM have been reported as more likely to harbor co-infections than heterosexual males, with the co-infection rate increasing with age in MSM, but decreasing with age in heterosexual men [73], while others have found similar co-infection rates for MSM and heterosexual men [74]. However, MSM have higher overall infection rates than heterosexual men, which may impact such analyses. Coinfection has, in most cases, been linked with increased risk of re-infections. Co-infection increases risk of (i) re-infection with $\mathrm{CT}$ or NG when retested between 6 weeks and 6 months [70], (ii) NG re-infection in a high NG prevalence population [71], and (iii) CT re-infection in women [75]. However, a study that collected daily samples for 28 days after antibiotic treatment, evaluating 23 patients with $\mathrm{NG} / \mathrm{CT}$ co-infection for CT clearance, noted $100 \%$ clearance with no re-infections [17].

CT/NG co-infection might increase NG transmission compared with single infection, owing to increased bacterial load, but not contribute to increased symptom severity [76•]. In a study of women aged 14-17 who collected 12 weekly selftaken vaginal swabs twice per year, 16 women acquired NG infection, demonstrating variable bacterial load over the ensuing 11 weeks, co-infection (in 6 of 13 cases) associated with increased NG bacterial load, and largely asymptomatic infection [76•]. However, studies based on concordance of infection status in couples have suggested that, though NG was generally found to be more transmissible than CT, coinfection had no effect on NG transmission [77], or even reduced NG transmission [78]. Genital symptoms were more common in CT/NG co-infection (16\%) than in single infections (NG 7.7\%, CT 5.0\%) among 568 high school students in the USA [68], but not among 382 STD clinic patients in the UK (CT/NG co-infection, 40\% asymptomatic; NG alone, $33 \%$ asymptomatic) [79].

Associations between CT/NG co-infection and damaging long-term sequelae are also variable. A study of CT and NG as well as Mycoplasma genitalium, Ureaplasma urealyticum/ parvum, Gardnerella vaginalis, Trichomonas vaginalis, and herpes simplex virus- $1 / 2$ found that CT and co-infections with two or more of the evaluated organisms were associated with similarly high risk of EP [80]. Similarly, risk of TFI was shown to be similar for single infection or $\mathrm{CT} / \mathrm{NG}$ coinfection [81], while others showed an increased risk of endometrial infection associated with $\mathrm{NG}$ co-infection, but not $M$. genitalium or T. vaginalis co-infection or bacterial vaginosis, in a group of CT-infected women [82]. Most studies only considered CT/NG infections [68, 76•, 77-79, 81] and did not consider/exclude other STIs and/or bacterial vaginosis, so their findings might be affected by unknown co-infections.

The potential for unknown co-infection variables to impact progress in vaccine development, perhaps the most pressing need to effectively control CT and NG, is becoming clear. A study published in 2017 provided the first evidence that a vaccine might protect against NG infection. A commercial vaccine for Neisseria meningitidis, used in a campaign in New Zealand in the early 2000s, had an estimated anti-NG vaccine efficacy (VE) of $31 \%$ [83]. VE was reduced in the case of $\mathrm{CT} / \mathrm{NG}$ co-infection [83], emphasizing the need for greater understanding of CT and NG biology. Basic science 
research plays an important role in informing clinical study design and helping to explain how one pathogen might affect the immune response to another. A study published in 2018 found that $\mathrm{CT}$ can prevent human neutrophils from producing neutrophil extracellular traps (NETs) in response to NG [84], providing interesting insights into the potential for $\mathrm{CT} / \mathrm{NG}$ interaction.

\section{In Vivo Infection and Co-infection: Animal Models of CT, NG, and CT/NG}

Animal models of CT and NG infection have been pivotal in understanding information we have gleaned from clinical and epidemiological studies. Clinical and mathematical modeling data demonstrate that human genital and rectal NG/CT coinfections are frequent and suggest active interplay between these two pathogens $[3 \cdot, 85]$. As most published experimental animal studies have focused on each pathogen individually, CT/NG co-infection models in which the pathophysiological consequences of co-infection can be explored are needed. There are several Chlamydia in vivo genital infection models, including (i) C. muridarum (CM), CT, and C. suis (CS) in mice; (ii) C. caviae (CC) in guinea pigs; (iii) C. suis in swine; and (iv) $\mathrm{CT}$ in several non-human primate species $[86 \cdot, 87$, $88,89 \cdot \bullet$. In contrast, the most well-established animal NG genital infection models are in mice and chimpanzees [90]. The most widely used NG mouse model, introduced almost 20 years ago and still currently in use, has been valuable in examining NG colonization kinetics, fitness, vaccine candidates, host immune response, influence of host estrus state on infection, and pharmacokinetics of gonorrhea therapeutic antimicrobials [69, 90-92]. To our knowledge, only one CT/ $N G$ co-infection animal model, a modification of the abovedescribed NG single-infection model, has been published to date. Vonck et al. vaginally $\mathrm{CM}$-infected BALB/c mice, prior to subsequent $17-\beta$-estradiol treatment and vaginal NG infection. Vancomycin (VAN) and streptomycin (STP) injections were used to suppress normal microflora and promote NG colonization. Viable $\mathrm{NG}$ and $\mathrm{CM}$ were recovered in vaginal swabs for 8-10 days, and significantly more gonococci were observed in co-infected compared with NG singly infected mice [93••]. Vaginal neutrophil numbers and leukocyte chemokine concentrations also increased in co-infected mice compared with either $\mathrm{CM}$ or NG singly infected mice, which may explain the more severe symptoms observed in coinfected women [94].

The murine model established by Vonck et al. has revealed interesting facets of co-infection, but the authors suggested two main limitations of the model, both due to specific requirements for robust NG infection. First, estradiol treatment is immunomodulatory, reducing vaginal cytokine expression in CM-infected mice [93••]. Second, VAN/STP treatment is required to suppress growth of vaginal microflora [93••]. Therefore, animal models that require neither exogenous hormone nor antibiotic administration would be advantageous. Transgenic mice expressing human carcinoembryonic antigen-related cell adhesion molecule 1 (hCEACAM1), a receptor for gonococcal Opa proteins, support vaginal NG colonization in the absence of estradiol treatment for at least 15 days [95]. As in the Vonck et al. study, VAN/STP treatment was used to suppress vaginal microflora. However, the authors did not report attempting NG infection without antibiotics [95], raising the possibility that VAN/STP treatment may not be required in hCEACAM1-expressing mice. Nonetheless, a NG mouse model that does not require estradiol treatment offers advantages, particularly for studying host immune responses to co-infection, even if VAN/STP treatment is required. Interestingly, a human NG clinical isolate has been shown to colonize, grow, and form biofilms on explanted pig vaginal tissue under aerobic conditions [96]. Given that epithelial cells within the NG-infected tissue remain viable despite extensive NG biofilm formation [96] and that CS readily infects explanted pig cervical and uterine luminal and glandular epithelial cells [97], an NG/CS co-infection model using explanted vaginal tissue seems feasible. These data also suggest that establishing genital co-infections in a female pig model is feasible because (i) a model of $C$. suis genital infection already exists and (ii) the porcine genital immune system and estrus cycle are more similar to those in humans than to those in the mouse $[88,89 \cdot \bullet]$.

Another approach to modeling co-infection is to use Neisseria or Neisseriaceae species that naturally colonize the genital tract of animal species that can also be Chlamydia infected. Uruburuella suis, a novel species in the family Neisseriaceae, was isolated from pigs with pneumonia and pericarditis in 2005 [89••, 98]. A new commensal Neisseria species (N. musculi) has also been recently identified in the wild house mouse $[99,100]$. N. musculi can be cultured and transformed to produce knockout and gene-complemented strains and colonizes the gut and oral mucosa of C57/B6 mice without producing overt disease. N. musculi colonization in mice requires neither estradiol or antibiotic treatment nor expression of human-specific receptors. The $N$. musculi genome also contains predicted homologs for several NG and $N$. meningitidis virulence factor-encoding genes [100]. Because CM establishes gastrointestinal infection in mice via the oral route [101, 102], co-infecting mice orally with $\mathrm{CM}$ and $N$. musculi should be relatively straightforward. A significant drawback to developing a Chlamydia/U. suis or $N$. musculi co-infection system is that neither Neisseriaceae species has been shown to colonize the genital tract of their host species. More importantly, each lacks key virulence factors present in NG-though select NG genes could be expressed in N. musculi. However, it seems likely that interactions 
between these pathogens might be radically different than those of NG and CT in the human genital tract.

A 2016 study demonstrated that the host nectin-1 protein is required for efficient murine genital $\mathrm{CM}$ infection but not for rectal infection [103], suggesting that host factors required for CM infection may vary at different anatomical sites. Thus, observations from in vivo studies of genital single infection or co-infection may not be entirely applicable to co-infections of the rectal mucosa. Interestingly, CM-infected mice exhibited attenuated tubal fibrosis in the absence of gastrointestinal CM carriage [104], suggesting that gastrointestinal CM infection influences distal genital tract pathology, at least in the context of the murine model. Rectal NG/CT co-infections occur in humans, and thus, it is desirable to develop experimental animal models of rectal co-infection. Though there is no established murine NG rectal infection model, the CM rectal infection model [103] provides a platform with which to attempt rectal $\mathrm{CM} / \mathrm{NG}$ co-infection in either male or female mice. Intestinal hCEACAM1 expression is observed in the hCEACAM1-transgenic mice described above [95], suggesting that these mice may be susceptible to rectal NG infection and could be used to establish a relevant co-infection model. Because significant physiologic differences are observed in female, versus male, animal models, it is also important to evaluate sex as a biologic variable during co-infection. Male mice and guinea pigs can be genitally infected with $\mathrm{CM}$ and $\mathrm{CC}$, respectively, and both models have the additional advantage that natural male to female transmission can be studied $[105,106]$. Though much needed, there is no established animal model for NG genital infection in males and, thus, no characterized system in which to attempt male genital co-infection. However, a rectal co-infection model in male mice, such as that discussed above, would inform whether there are host sex-specific differences in the progression or outcome of Chlamydia/NG co-infection.

\section{Conclusions}

$\mathrm{CT}$ and NG are common bacterial sexually transmitted pathogens and CT/NG co-infections are also common. Both primarily infect the female endocervix and male urethra and share many clinical characteristics. Differences in the biology and infection dynamics of CT and NG, however, contribute to differences in their epidemiology and to challenges for management and control in highincome countries. For CT, high prevalence in the general population of young heterosexual adults makes screening of asymptomatic people an attractive intervention. However, prevalence has not, thus far, decreased in high-income countries that recommend screening. Rectal CT infection in women is hypothesized as a reason for sustained prevalence, but its clinical relevance has yet to be shown convincingly. NG is uncommon in the general heterosexual population, but incidence is increasing among
MSM. The spread of antimicrobial resistance in NG is a serious threat to control, with verified exceedingly difficult-to-treat cases and untreatable NG cases likely in the near future. Pharyngeal NG is common in MSM and may be a niche where resistance development is promoted. There is surprisingly little epidemiological research about CT/NG co-infection. Mathematical modeling studies suggest that each infection could increase susceptibility and/or transmissibility of the other, and bacterial load might be higher in CT/NG co-infection than in NG alone. The vaginal microbiome probably influences the risks of $\mathrm{CT}$ and $\mathrm{NG}$ and hence CT/NG co-infection as well. With increasing interest in the development of new treatments and vaccines against NG and $\mathrm{CT}$, it will be important to investigate their effectiveness in the context of co-infections. Finally, future advances will require studies in animal models. There are substantial challenges, however, because both CT and NG are human-specific pathogens. Appropriate, quality-assured animal models are essential to improve understanding of the pathogenic interplay in $\mathrm{CT} / \mathrm{NG}$ coinfections.

Author Contributions All authors contributed to the literature review, writing, reading, and approving the manuscript.

Funding Information This work was financially supported by the Swiss National Science Foundation (SNSF) (grant 310030_179391), by the Department of Biomedical Sciences, Quillen College of Medicine, and by the Inflammation and Immunity HIV Pilot Grant from the Center for Infectious Disease, East Tennessee State University.

\section{Compliance with Ethical Standards}

Conflict of Interest The authors declare that they have no competing interests.

Human and Animal Rights and Informed Consent This article does not contain any studies with human or animal subjects performed by any of the authors.

Open Access This article is distributed under the terms of the Creative Commons Attribution 4.0 International License (http:// creativecommons.org/licenses/by/4.0/), which permits unrestricted use, distribution, and reproduction in any medium, provided you give appropriate credit to the original author(s) and the source, provide a link to the Creative Commons license, and indicate if changes were made.

\section{References}

Papers of particular interest, published recently, have been highlighted as:

- Of importance

•. Of major importance

1. WHO. Report on global sexually transmitted infection surveillance. https://www.who.int/reproductivehealth/publications/stissurveillance-2018/en/ Accessed 20 May 20019. 
2. Holmes KK, editor. Sexually transmited diseases. 4th ed. New York: McGraw Hill Medical; 2008.

3. Althaus CL, KME T, Mercer CH, Auguste P, Roberts TE, Bell G, et al. Effectiveness and cost-effectiveness of traditional and new partner notification technologies for curable sexually transmitted infections: observational study, systematic reviews and mathematical modelling. Health Technol Assess. 2014;18:1-99. https://doi. org/10.3310/hta18020. A comprehensive review of clinical CT/ NG co-infection studies and mathematical modeling highlights potential CT/NG biological interaction.

4. Low N, Redmond S, Uusküla A, van Bergen J, Ward H, Andersen $\mathrm{B}$, et al. Screening for genital chlamydia infection. Cochrane Database Syst Rev. 2016;9:CD010866. https://doi.org/10.1002/ 14651858.CD010866.pub2.

5. Redmond SM, Alexander-Kisslig K, Woodhall SC, van den Broek IVF, van Bergen J, Ward H, et al. Genital chlamydia prevalence in Europe and non-European high income countries: systematic review and meta-analysis. PLoS One. 2015;10:e0115753. https:// doi.org/10.1371/journal.pone.0115753.

6. CDC. Sexually transmitted disease surveillance 2017. https:// www.cdc.gov/std/stats Accessed 20 May 2019.

7. Goller JL, De Livera AM, Fairley CK, Guy RJ, Bradshaw CS, Chen MY, et al. Population attributable fraction of pelvic inflammatory disease associated with chlamydia and gonorrhoea: a cross-sectional analysis of Australian sexual health clinic data. Sex Transm Infect. 2016;92:525-31. https://doi.org/10.1136/ sextrans-2015-052195.

8. Dudareva-Vizule S, Haar K, Sailer A, Wisplinghoff H, Wisplinghoff F, Marcus U, et al. Prevalence of pharyngeal and rectal Chlamydia trachomatis and Neisseria gonorrhoeae infections among men who have sex with men in Germany. Sex Transm Infect. 2014;90:46-51. https://doi.org/10.1136/sextrans2012-050929.

9. Ota KV, Tamari IE, Smieja M, Jamieson F, Jones KE, Towns L, et al. Detection of Neisseria gonorrhoeae and Chlamydia trachomatis in pharyngeal and rectal specimens using the BD Probetec ET system, the Gen-Probe Aptima Combo 2 assay and culture. Sex Transm Infect. 2009;85:182-6. https://doi.org/10. 1136/sti.2008.034140.

10. van Liere GAFS, Hoebe CJPA, Dukers-Muijrers NHTM. Evaluation of the anatomical site distribution of chlamydia and gonorrhoea in men who have sex with men and in high-risk women by routine testing: cross-sectional study revealing missed opportunities for treatment strategies. Sex Transm Infect. 2014;90: 58-60. https://doi.org/10.1136/sextrans-2013-051248.

11. van Liere GAFS, Hoebe CJPA, Wolffs PFG, Dukers-Muijrers NHTM. High co-occurrence of anorectal chlamydia with urogenital chlamydia in women visiting an STI clinic revealed by routine universal testing in an observational study; a recommendation towards a better anorectal chlamydia control in women. BMC Infect Dis. 2014;14:274. https://doi.org/10.1186/1471-2334-14274.

12. WHO. WHO guidelines for the treatment of Chlamydia trachomatis. https://www.who.int/reproductivehealth/ publications/rtis/chlamydia-treatment-guidelines/en/. Accessed 20 May 2019.

13. Workowski KA, Bolan GA. Sexually transmitted diseases treatment guidelines, 2015. Morbidity and mortality weekly report (MMWR). 2015;64(RR-03):1 https://wwwedcgov/mmwr/ preview $/ \mathrm{mmwrhtml} / \mathrm{rr} 6403 \mathrm{a} 1 \mathrm{htm}$. Accessed 20 May 2019.

14. Lanjouw E, Ouburg S, de Vries HJ, Stary A, Radcliffe K, Unemo M. 2015 European guideline on the management of Chlamydia trachomatis infections. Int J STD AIDS. 2016;27:333-48. https:// doi.org/10.1177/0956462415618837.

15. Borel N, Leonard C, Slade J, Schoborg RV. Chlamydial antibiotic resistance and treatment failure in veterinary and human medicine.
Curr Clin Microbiol Reports. 2016;3:10-8. https://doi.org/10. 1007/s40588-016-0028-4.

16. Wi T, Lahra MM, Ndowa F, Bala M, Dillon J-AR, Ramon-Pardo $\mathrm{P}$, et al. Antimicrobial resistance in Neisseria gonorrhoeae: global surveillance and a call for international collaborative action. PLOS Med. 2017;14:e1002344. https://doi.org/10.1371/journal.pmed. 1002344.

17. Wind CM, Schim van der Loeff MF, Unemo M, Schuurman R, van Dam AP, de Vries HJC. Time to clearance of Chlamydia trachomatis RNA and DNA after treatment in patients coinfected with Neisseria gonorrhoeae - a prospective cohort study. BMC Infect Dis. 2016;16:554. https://doi.org/10.1186/s12879-0161878-3.

18. Batteiger BE, Tu W, Ofner S, Van Der Pol B, Stothard DR, Orr DP, et al. Repeated Chlamydia trachomatis genital infections in adolescent women. J Infect Dis. 2010;201:42-51. https://doi.org/10. 1086/648734.

19. Unemo M, Bradshaw CS, Hocking JS, de Vries HJC, Francis SC, Mabey D, et al. Sexually transmitted infections: challenges ahead. Lancet Infect Dis. 2017:e235-79. https://doi.org/10.1016/S14733099(17)30310-9.

20. Van Liere GAFS, Dukers-Muijrers NHTM, Levels L, Hoebe CJPA. High proportion of anorectal Chlamydia trachomatis and Neisseria gonorrhoeae after routine universal urogenital and anorectal screening in women visiting the sexually transmitted infection clinic. Clin Infect Dis. 2017;64:1705-10. https://doi. org $/ 10.1093 / \mathrm{cid} / \mathrm{cix} 243$.

21. Andersson N, Boman J, Nylander E. Rectal chlamydia - should screening be recommended in women? Int J STD AIDS. 2017;28: 476-9. https://doi.org/10.1177/0956462416653510.

22. Dukers-Muijrers NHTM, Schachter J, van Liere GAFS, Wolffs PFG, Hoebe CJPA. What is needed to guide testing for anorectal and pharyngeal Chlamydia trachomatis and Neisseria gonorrhoeae in women and men? Evidence and opinion. BMC Infect Dis. 2015;15:533. https://doi.org/10.1186/s12879-015-1280-6.

23. Chandra NL, Broad C, Folkard K, Town K, Harding-Esch EM, Woodhall SC, et al. Detection of Chlamydia trachomatis in rectal specimens in women and its association with anal intercourse: a systematic review and meta-analysis. Sex Transm Infect. 2018;94: 320-6. https://doi.org/10.1136/sextrans-2017-053161.

24. Rank RG, Yeruva L. Hidden in plain sight: chlamydial gastrointestinal infection and its relevance to persistence in human genital infection. Infect Immun. 2014;82:1362-71. https://doi.org/10. 1128/IAI.01244-13.

25. Kong FYS, Tabrizi SN, Fairley CK, Vodstrcil LA, Huston WM, Chen M, et al. The efficacy of azithromycin and doxycycline for the treatment of rectal chlamydia infection: a systematic review and meta-analysis. J Antimicrob Chemother. 2015;70:1290-7. https://doi.org/10.1093/jac/dku574.

26. Borel N, Marti H, Pospischil A, Pesch T, Prähauser B, Wunderlin $\mathrm{S}$, et al. Chlamydiae in human intestinal biopsy samples. Pathog Dis. 2018;76. https://doi.org/10.1093/femspd/fty081.

27. Dukers-Muijrers NHTM, Wolffs PFG, Eppings L, Götz HM, Bruisten SM, Schim van der Loeff MF, et al. Design of the FemCure study: prospective multicentre study on the transmission of genital and extra-genital Chlamydia trachomatis infections in women receiving routine care. BMC Infect Dis. 2016;16:381. https://doi.org/10.1186/s12879-016-1721-x.

28. van den Broek IV, Sfetcu O, van der Sande MA, Andersen B, Herrmann B, Ward H, et al. Changes in chlamydia control activities in Europe between 2007 and 2012: a cross-national survey. Eur J Pub Health. 2016;26:382-8. https://doi.org/10.1093/ EURPUB/CKV196.

29. Workowski K. Chlamydia and gonorrhea. Ann Intern Med. 2013;158:ITC2. https://doi.org/10.7326/0003-4819-158-3201302050-01002. 
30. Low N. Screening programmes for chlamydial infection: when will we ever learn? BMJ. 2007;334:725-8. https://doi.org/10. 1136/bmj.39154.378079.BE.

31. Sonnenberg P, Clifton S, Beddows S, Field N, Soldan K, Tanton $\mathrm{C}$, et al. Prevalence, risk factors, and uptake of interventions for sexually transmitted infections in Britain: findings from the National Surveys of Sexual Attitudes and Lifestyles (Natsal). Lancet. 2013;382:1795-806. https://doi.org/10.1016/S01406736(13)61947-9.

32. Datta SD, Torrone E, Kruszon-Moran D, Berman S, Johnson R, Satterwhite CL, et al. Chlamydia trachomatis trends in the United States among persons 14 to 39 years of age, 1999-2008. Sex Transm Dis. 2012;39:92-6. https://doi.org/10.1097/OLQ. 0b013e31823e2ff7.

33. van den Broek IVF, van Bergen JEAM, Brouwers EEHG, Fennema JSA, Götz HM, Hoebe CJPA, et al. Effectiveness of yearly, register based screening for chlamydia in the Netherlands: controlled trial with randomised stepped wedge implementation. BMJ. 2012;345:e4316. https://doi.org/10.1136/ BMJ.E4316.

34. Hocking JS, Temple-Smith M, Guy R, Donovan B, Braat S, Law $\mathrm{M}$, et al. Population effectiveness of opportunistic chlamydia testing in primary care in Australia: a cluster-randomised controlled trial. Lancet. 2018;392:1413-22. https://doi.org/10.1016/S01406736(18)31816-6.

35. Woodhall SC, Soldan K, Sonnenberg P, Mercer CH, Clifton S, Saunders $\mathrm{P}$, et al. Is chlamydia screening and testing in Britain reaching young adults at risk of infection? Findings from the third National Survey of Sexual Attitudes and Lifestyles (Natsal-3). Sex Transm Infect. 2016;92:218-27. https://doi.org/10.1136/sextrans2015-052013.

36. Gottlieb SL, Martin DH, Xu F, Byrne GI, Brunham RC. Summary: the natural history and immunobiology of Chlamydia trachomatis genital infection and implications for chlamydia control. J Infect Dis. 2010;201:190-204. https://doi.org/10.1086/ 652401.

37. Zheng X, O'Connell CM, Zhong W, Nagarajan UM, Tripathy M, Lee D, et al. Discovery of blood transcriptional endotypes in women with pelvic inflammatory disease. J Immunol. 2018;200:294156. https://doi.org/10.4049/jimmunol.1701658.

38. Tamarelle J, Thiébaut ACM, de Barbeyrac B, Bébéar C, Ravel J, Delarocque-Astagneau E. The vaginal microbiota and its association with human papillomavirus, Chlamydia trachomatis, Neisseria gonorrhoeae and Mycoplasma genitalium infections: a systematic review and meta-analysis. Clin Microbiol Infect. 2019: 35-47. https://doi.org/10.1016/j.cmi.2018.04.019.

39. Van Der Pol B, Daniel G, Kodsi S, Paradis S, Cooper CK. Molecular-based testing for sexually transmitted infections using samples previously collected for vaginitis diagnosis. Clin Infect Dis. 2019;68:375-81. https://doi.org/10.1093/cid/ciy504.

40. van de Wijgert JHHM. The vaginal microbiome and sexually transmitted infections are interlinked: consequences for treatment and prevention. PLoS Med. 2017;14:e1002478. https://doi.org/10. 1371/journal.pmed.1002478.

41. Keith JW, Pamer EG. Enlisting commensal microbes to resist antibiotic-resistant pathogens. J Exp Med. 2018;216: jem.20180399. https://doi.org/10.1084/jem.20180399.

42. Torrone EA, Johnson RE, Tian LH, Papp JR, Datta SD, Weinstock HS. Prevalence of Neisseria gonorrhoeae among persons 14 to 39 years of age, United States, 1999 to 2008. Sex Transm Dis. 2013;40:202-5. https://doi.org/10.1097/OLQ. 0b013e31827c5a71.

43. ECDC. Surveillance atlas of infectious diseases. https://atlas.ecdc. europa.eu/public/index.aspx. Accessed 17 May 2019.

44. Weström L V. Sexually transmitted diseases and infertility. Sex Transm Dis. 1994; S32-7.
45. Day MJ, Spiteri G, Jacobsson S, Woodford N, Amato-Gauci AJ, Cole MJ, et al. Stably high azithromycin resistance and decreasing ceftriaxone susceptibility in Neisseria gonorrhoeae in 25 European countries, 2016. BMC Infect Dis. 2018;18:609. https://doi.org/10. 1186/s12879-018-3528-4.

46. Chisholm SA, Wilson J, Alexander S, Tripodo F, Al-Shahib A, Schaefer U, et al. An outbreak of high-level azithromycin resistant Neisseria gonorrhoeae in England. Sex Transm Infect. 2016;92: 365-7. https://doi.org/10.1136/sextrans-2015-052312.

47. Unemo M, Nicholas RA. Emergence of multidrug-resistant, extensively drug-resistant and untreatable gonorrhea. Future Microbiol. 2012;7:1401-22. https://doi.org/10.2217/fmb.12.117.

48. Bolan GA, Sparling PF, Wasserheit JN. The emerging threat of untreatable gonococcal infection. N Engl J Med. 2012;366:485-7. https://doi.org/10.1056/nejmp1112456.

49. Unemo M, Shafer WM. Antimicrobial resistance in Neisseria gonorrhoeae in the 21st century: past, evolution, and future. Clin Microbiol Rev. 2014;27:587-613. https://doi.org/10.1128/CMR. 00010-14.

50. Weston EJ, Kirkcaldy RD, Stenger M, Llata E, Hoots B, Torrone EA. Narrative review: assessment of Neisseria gonorrhoeae infections among men who have sex with men in national and sentinel surveillance systems in the United States. Sex Transm Dis. 2017;45:1. https://doi.org/10.1097/OLQ.0000000000000740.

51. Mohammed H, Mitchell H, Sile B, Duffell S, Nardone A, Hughes G. Increase in sexually transmitted infections among men who have sex with men, England, 2014. Emerg Infect Dis. 2016;22: 88-91. https://doi.org/10.3201/eid2201.151331.

52. Traeger MW, Cornelisse VJ, Asselin J, Price B, Roth NJ, Willcox $\mathrm{J}$, et al. Association of HIV preexposure prophylaxis with incidence of sexually transmitted infections among individuals at high risk of HIV infection. JAMA. 2019;321:1380. https://doi.org/10. 1001/jama.2019.2947.

53. Doherty IA, Padian NS, Marlow C, Aral SO. Determinants and consequences of sexual networks as they affect the spread of sexually transmitted infections. J Infect Dis. 2005;191:S42-54. https://doi.org/10.1086/425277.

54. Tsoumanis A, Hens N, Kenyon CR. Is screening for chlamydia and gonorrhea in men who have sex with men associated with reduction of the prevalence of these infections? A systematic review of observational studies. Sex Transm Dis. 2018;45:615-22. https://doi.org/10.1097/OLQ.0000000000000824.

55. Fingerhuth SM, Bonhoeffer S, Low N, Althaus CL. Antibioticresistant Neisseria gonorrhoeae spread faster with more treatment, not more sexual partners. Levin BR, editor. PLOS Pathog. 2016;12: e1005611. https://doi.org/10.1371/journal.ppat. 1005611

56. Kenyon C, Buyze J, Spiteri G, Cole MJ, Unemo M. Populationlevel antimicrobial consumption is associated with decreased antimicrobial susceptibility in Neisseria gonorrhoeae in 24 European countries: an ecological analysis. J Infect Dis. 2019. https://doi. org/10.1093/infdis/jiz153.

57. Bell BG, Schellevis F, Stobberingh E, Goossens H, Pringle M. A systematic review and meta-analysis of the effects of antibiotic consumption on antibiotic resistance. BMC Infect Dis. 2014;14: 13. https://doi.org/10.1186/1471-2334-14-13.

58. Olesen SW, Grad YH. Deciphering the impact of bystander selection for antibiotic resistance in Neisseria gonorrhoeae. J Infect Dis. 2019. https://doi.org/10.1093/infdis/jiz156.

59. Abraha M, Egli-Gany D, Low N. Epidemiological, behavioural, and clinical factors associated with antimicrobial-resistant gonorrhoea: a review. F1000Res. 2018;7:400. https://doi.org/10. 12688/f1000research.13600.1.

60. Whittles LK, Didelot X, Grad YH, White PJ. Testing for gonorrhoea should routinely include the pharynx. Lancet Infect 
Dis. 2018;18:716-7. https://doi.org/10.1016/S1473-3099(18) 30341-4.

61. Chow EPF, Cornelisse VJ, Williamson DA, Priest D, Hocking JS, Bradshaw CS, et al. Kissing may be an important and neglected risk factor for oropharyngeal gonorrhoea: a cross-sectional study in men who have sex with men. Sex Transm Infect. 2019. https:// doi.org/10.1136/sextrans-2018-053896.

62. Fairley CK, Hocking JS, Zhang L, Chow EPF. Frequent transmission of gonorrhea in men who have sex with men. Emerg Infect Dis. 2017;23:102-4. https://doi.org/10.3201/eid2301.161205.

63. Bamberger DM, Graham G, Dennis L, Gerkovich MM. Extragenital gonorrhea and chlamydia among men and women according to type of sexual exposure. Sex Transm Dis. 2019;46: 329-34. https://doi.org/10.1097/OLQ.0000000000000967.

64. Hananta IPY, de Vries HJC, van Dam AP, van Rooijen MS, Soebono H. Schim van der Loeff MF. Spontaneous clearance of pharyngeal gonococcal infections. Sex Transm Dis. 2018;45:1. https://doi.org/10.1097/OLQ.0000000000000807.

65. Cornelisse VJ, Zhang L, Law M, Chen MY, Bradshaw CS, Bellhouse C, et al. Concordance of gonorrhoea of the rectum, pharynx and urethra in same-sex male partnerships attending a sexual health service in Melbourne, Australia. BMC Infect Dis. 2018;18:95. https://doi.org/10.1186/s12879-018-3003-2.

66. Lewis DA. Will targeting oropharyngeal gonorrhoea delay the further emergence of drug-resistant Neisseria gonorrhoeae strains? Sex Transm Infect. 2015;91:234-7. https://doi.org/10.1136/ sextrans-2014-051731.

67. Creighton S, Tenant-Flowers M, Taylor CB, Miller R, Low N. Coinfection with gonorrhea and chlamydia: how much is there and what does it mean? Int J STD AIDS. 2003;14:109-13.

68. Nsuami M, Cammarata CL, Brooks BN, Taylor SN, Martin DH. Chlamydia and gonorrhea co-occurrence in a high school population. Sex Transm Dis. 2004;31:424-7. https://doi.org/10.1097/01. OLQ.0000130535.96576.D3.

69. Vincent LR, Jerse AE. Biological feasibility and importance of a gonorrhea vaccine for global public health. Vaccine. 2018. https:// doi.org/10.1016/j.vaccine.2018.02.081

70. Rose SB, Garrett SM, Stanley J, Pullon SRH. Retesting and repeat positivity following diagnosis of Chlamydia trachomatis and Neisseria gonorrhoea in New Zealand: a retrospective cohort study. BMC Infect Dis. 2017;17:526. https://doi.org/10.1186/ s12879-017-2635-y.

71. Trecker MA, Dillon J-AR, Lloyd K, Hennink M, Jolly A, Waldner C. Can social network analysis help address the high rates of bacterial sexually transmitted infections in Saskatchewan? Sex Transm Dis. 2017;44:338-43. https://doi.org/10.1097/OLQ. 0000000000000599

72. Trecker MA, Dillon JAR, Lloyd K, Hennink M, Waldner CL. Demographic and behavioural characteristics predict bacterial STI reinfection and coinfection among a cross-sectional sample of laboratory-confirmed gonorrhea cases in a local health region from Saskatchewan, Canada. Can J Public Heal. 2015;106:e1721. https://doi.org/10.17269/CJPH.106.4792.

73. Zhang J, Van Der Veen S. Neisseria gonorrhoeae 23S rRNA A2059G mutation is the only determinant necessary for highlevel azithromycin resistance and improves in vivo biological fitness. J Antimicrob Chemother. 2019;74:407-15. https://doi.org/ 10.1093/jac/dky438.

74. Khaw C, Li B, Waddell R. Epidemiological treatment for chlamydia co-infection in men who have sex with men (MSM) with a presumptive diagnosis of urethral gonorrhoea in South Australia. Sex Transm Infect. 2012;88:580. https://doi.org/10.1136/sextrans2012-050687.

75. Hillis SD, Nakashima A, Marchbanks PA, Addiss DG, Davis JP. Risk factors for recurrent Chlamydia trachomatis infections in women. Am J Obstet Gynecol Mosby. 1994;170:801-6. https:// doi.org/10.1016/S0002-9378(94)70286-1.

76. Stupiansky NW, Van Der Pol B, Williams JA, Weaver B, Taylor SE, Fortenberry JD. The natural history of incident gonococcal infection in adolescent women. Sex Transm Dis. 2011;38:750-4. https://doi.org/10.1097/OLQ.0b013e31820ff9a4. Clinical study of naturally occurring NG infection indicates that CT coinfection increases NG load in women.

77. Lin JL, Donegan SP, Heeren TC, Greenberg M, Flaherty EE, Haivanis R, et al. Transmission of Chlamydia trachomatis and Neisseria gonorrhoeae among men with urethritis and their female sex partners. J Infect Dis. 1998;178:1707-12. https://doi.org/10. $1086 / 314485$.

78. Lycke E, Löwhagen GB, Hallhagen G, Johannisson G, Ramstedt $\mathrm{K}$. The risk of transmission of genital Chlamydia trachomatis infection is less than that of genital Neisseria gonorrhoeae infection. Sex Transm Dis. 1980;7:6-10.

79. David LM, Wade AAH, Natin D, Radcliffe KW. Gonorrhoea in Coventry 1991-1994: epidemiology, coinfection and evaluation of partner notification in the STD clinic. Int J STD AIDS. 1997;8: 311-6. https://doi.org/10.1258/0956462971920154.

80. Ashshi AM, Batwa SA, Kutbi SY, Malibary FA, Batwa M, Refaat B. Prevalence of 7 sexually transmitted organisms by multiplex real-time PCR in fallopian tube specimens collected from Saudi women with and without ectopic pregnancy. BMC Infect Dis. 2015;15:569. https://doi.org/10.1186/s12879-015-1313-1.

81. Reekie J, Donovan B, Guy R, Hocking JS, Kaldor JM, Mak D, et al. Risk of ectopic pregnancy and tubal infertility following gonorrhea and chlamydia infections. Clin Infect Dis. 2019. https://doi.org/10.1093/cid/ciz145.

82. Russell AN, Zheng X, O'Connell CM, Taylor BD, Wiesenfeld $\mathrm{HC}$, Hillier SL, et al. Analysis of factors driving incident and ascending infection and the role of serum antibody in Chlamydia trachomatis genital tract infection. J Infect Dis. 2016;213:523-31. https://doi.org/10.1093/infdis/jiv438.

83. Petousis-Harris H, Paynter J, Morgan J, Saxton P, McArdle B, Goodyear-Smith F, et al. Effectiveness of a group B outer membrane vesicle meningococcal vaccine against gonorrhoea in New Zealand: a retrospective case-control study. Lancet. 2017;390: 1603-10. https://doi.org/10.1016/S0140-6736(17)31449-6.

84. Rajeeve K, Das S, Prusty BK, Rudel T. Chlamydia trachomatis paralyses neutrophils to evade the host innate immune response. Nat Microbiol. 2018;3:824-35. https://doi.org/10.1038/s41564018-0182-y.

85. Creighton S. Gonorrhoea. BMJ Clin Evid. 2014:2014.

86. De Clercq E, Kalmar I, Vanrompay D. Animal models for studying female genital tract infection with Chlamydia trachomatis. Infect Immun. 2013;81:3060-7. https://doi.org/10.1128/IAI. 00357-13. Concise overview of CT animal infection models.

87. Donati M, di Paolo MD, Favaroni A, Aldini R, di Francesco A, Ostanello F, et al. A mouse model for Chlamydia suis genital infection. Pathog Dis. 2015;73:1-3. https://doi.org/10.1093/ femspd/ftu017.

88. Lorenzen E, Follmann F, Jungersen G, Agerholm JS. A review of the human vs. porcine female genital tract and associated immune system in the perspective of using minipigs as a model of human genital chlamydia infection. Vet Res. 2015;46:116. https://oi.org/ 10.1186/s13567-015-0241-9.

89.• Käser T, Renois F, Wilson HL, Cnudde T, Gerdts V, Dillon J-AR, et al. Contribution of the swine model in the study of human sexually transmitted infections. Infect Genet Evol. 2018;66:34660. https://doi.org/10.1016/J.MEEGID.2017.11.022. Comprehensive review of advantages and disadvantages of swine to model STI pathophysiology.

90. Rice PA, Shafer WM, Ram S, Jerse AE. Neisseria gonorrhoeae : drug resistance, mouse models, and vaccine development. Annu 
Rev Microbiol. 2017;71:665-86. https://doi.org/10.1146/annurevmicro-090816-093530.

91. Connolly KL, Eakin AE, Gomez C, Osborn BL, Unemo M, Jerse AE. Pharmacokinetic data are predictive of in vivo efficacy for cefixime and ceftriaxone against susceptible and resistant Neisseria gonorrhoeae strains in the gonorrhea mouse model. Antimicrob Agents Chemother. 2019;63:e01644-18. https://doi. org/10.1128/AAC.01644-18.

92. Jerse AE. Experimental gonococcal genital tract infection and opacity protein expression in estradiol-treated mice experimental gonococcal genital tract infection and opacity protein expression in estradiol-treated mice. Infect Immun. 1999;67:5699-708.

93.•• Vonck RA, Darville T, O'Connell CM, Jerse AE. Chlamydial infection increases gonococcal colonization in a novel murine coinfection model. Infect Immun. 2011;79:1566-77. https://doi. org/10.1128/IAI.01155-10. The only currently established animal model for genital chlamydia/NG co-infection demonstrates that $\mathrm{CM}$ co-infection increases NG load in female mice.

94. Jerse AE, Wu H, Packiam M, Vonck RA, Begum AA, Garvin LE. Estradiol-treated female mice as surrogate hosts for Neisseria gonorrhoeae genital tract infections. Front Microbiol. 2011;2:113. https://doi.org/10.3389/fmicb.2011.00107.

95. Li G, Jiao H, Yan H, Wang J, Wang X, Ji M. Establishment of a human CEACAM1 transgenic mouse model for the study of gonococcal infections. J Microbiol Methods. 2011;87:350-4. https:// doi.org/10.1016/j.mimet.2011.09.012.

96. Breshears LM, Edwards VL, Ravel J, Peterson ML. Lactobacillus crispatus inhibits growth of Gardnerella vaginalis and Neisseria gonorrhoeae on a porcine vaginal mucosa model. BMC Microbiol. 2015;15:276. https://doi.org/10.1186/s12866-0150608-0.

97. Guseva NV, Knight ST, Whittimore JD, Wyrick PB. Primary cultures of female swine genital epithelial cells in vitro: a new approach for the study of hormonal modulation of chlamydia infection. Infect Immun. 2003;71:4700-10. https://doi.org/10.1128/ IAI.71.8.4700-4710.2003.

98. Vela AI, Collins MD, Lawson PA, García N, Domínguez L, Fernández-Garayzábal JF. Uruburuella suis gen. nov., sp. nov., isolated from clinical specimens of pigs. Int J Syst Evol Microbiol. 2005;55:643-7. https://doi.org/10.1099/ijs.0.63346-0.
99. Weyand NJ, Ma M, Phifer-Rixey M, Taku NA, Rendón MA, Hockenberry AM, et al. Isolation and characterization of Neisseria musculi sp. nov., from the wild house mouse. Int $\mathbf{J}$ Syst Evol Microbiol. 2016;66:3585-93. https://doi.org/10.1099/ ijsem.0.001237.

100. Ma M, Powell DA, Weyand NJ, Rhodes KA, Rendón MA, Frelinger JA, et al. A natural mouse model for Neisseria colonization. Infect Immun. 2018;86. https://doi.org/10.1128/iai.0083917.

101. Perry LL, Hughes S. Chlamydial colonization of multiple mucosae following infection by any mucosal route. Infect Immun. 1999;67:3686-9.

102. Yeruva L, Spencer N, Bowlin AK, Wang Y, Rank RG. Chlamydial infection of the gastrointestinal tract: a reservoir for persistent infection. Pathog Dis. 2013;68:88-95. https://doi.org/10.1111/ 2049-632X.12052.

103. Slade JA, Hall JV, Kintner J, Phillips-Campbell R, Schoborg RV. Host nectin-1 promotes chlamydial infection in the female mouse genital tract, but is not required for infection in a novel male murine rectal infection model. PLoS One. 2016;11:e0160511. https://doi.org/10.1371/journal.pone.0160511.

104. Zhong G. Chlamydia spreading from the genital tract to the gastrointestinal tract - a two-hit hypothesis. Trends Microbiol. 2018;26:611-23. https://doi.org/10.1016/j.tim.2017.12.002.

105. Mount DT, Bigazzi PE, Barron AL. Experimental genital infection of male guinea pigs with the agent of guinea pig inclusion conjunctivitis and transmission to females. Infect Immun. 1973;8: 925-30.

106. Pal S, Tifrea DF, de la Maza L. Characterization of the horizontal and vertical sexual transmission of chlamydia genital infections in a new mouse model. Infect Immun. 2019. https://doi.org/10.1128/ IAI.00834-18.

Publisher's Note Springer Nature remains neutral with regard to jurisdictional claims in published maps and institutional affiliations. 